\title{
The Researches about Makeup and Selection Optimization of Shale Gas Production Casing
}

\author{
Hua Tong ${ }^{1}$, Xiao-Hong Tang', Xiao-Hua Zhu ${ }^{1}$ \\ Mechanical and Electrical Engineering, Southwest Petroleum University, Chengdu, Sichuan, China
}

\begin{abstract}
The mining of Shale gas demands for extreme sealing performance of casing, while the size of make-up torque will determine the initial sealing performance of casing. At present, there are seldom researches how the make-up torque affects casing threads connection strength and sealing performance. Based on the deformation compatibility principle of internal and external casing threads, derived a formula about load distribution of unusual casing thread after clicked; Established three-dimensional computational models of TP-CQ, developed only by Tianjin, and API Buttress Casing; By computational analysis, obtained the best make-up torque of the two casings. Studied the stress and contact pressures distribution while casing threads are under composite loads (inner pressure, outer pressure, tension, bending); Drawn some stress and contact pressures distribution curve for this two casing after a lot of calculation, besides optimized selection of the corresponding depth of the casing.
\end{abstract}

Keyword: shale gas horizontal well; make-up torque; connection strength of joint; sealing performance; selection optimization

\section{Introduction}

As the hydrocarbon resources tend to be scarce, shale gas has become the focus on one of the world's new energy researches. It is of increasing importance for China to research and explore shale gas. CNPC, China National Petroleum Corporation, and Sinopec have been exploring actively in southern Sichuan Basin and other. The single well production of Fuling, national demonstration zone of Sinopec, reached $150,000 \mathrm{~m}^{3} / \mathrm{d}$ on average in 2013.But there has been appearing a quantity of engineering problems on shale gas mining process. For example, borehole face stability of argillutite layer is poor; Horizontal well has so complex wellbore that it is difficult to construct; Fracturing requires more strength of the production casing and high quality of well-cementation; Some well completion is without high quality - well construction cycle is too long and with high cost.

The Chinese scholars also have done a large of research about arising problem. Wang, et al, 2000, made gluing failure analysis of API round thread casing connection; Guo, 2013, put forward the casing gas tight detection principle; Wang, et al, 2011, made researches on problem which China confronted from in prospecting shale gas and pointed out the relevant countermeasures; Yu, 2014, established a two-dimensional plane strain model about casing failure of shale gas fracturing process; Yang, 2012, construed the centralized and tripping-in ability of shale gas well casing.

Currently here emerges another serious problem whether Shale gas mining uses API pipe or unusual casing. API pipe with secondary seal by threads grease can apply to some jobs in shallow, while with the increasing of well depth or in casing curvature, API pipe is no longer applicable. Unusual casing has collar with sealing face and shoulder but API pipe not, depicted in Figure1, which contributes to more advantages than API pipe in some complex conditions. The problem is that unusual casing will be more expensive than API pipe by 300,000 per well, on average, which is a high cost. To make the most benefits of the shale gas mining, how we make a choice between the two casings?

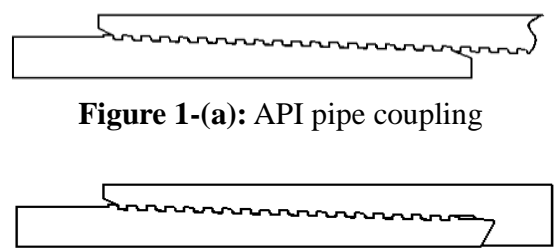

Figure 1-(b): unusual casing coupling

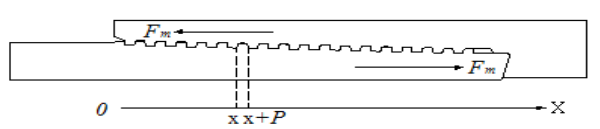

Figure 2: Force diagrams of unusual casing under preload

\section{Make-Up Torque Affects Load Distribution of Unusual Casing Threads}

Preload will be applied by make-up torque to connect casing and collar before unusual casing is set to the bottom of well, the forces of internal and external threads shown in Figure 2. Take a one-dimensional coordinate $\mathrm{OX}$, whose origin is on the large end of the external threads. Make the following assumptions, joint in the $\mathrm{x}$-cross section is subjected to axial load $\mathrm{F}\left({ }^{X}\right)$, and load density along the $\mathrm{x}$ direction is $\mathrm{f}(\mathrm{x})$. Load in the $\mathrm{x}$ direction of joint section changes for the deformation of the threads, so that $\mathrm{f}(\mathrm{x})$ also shows the distribution of the load between the turns of the threads. Then equation can be obtained

$$
\mathrm{F}(x)=\int_{0}^{x} f(x) \mathrm{d} x
$$

According to the assumption, the threads load at $\mathrm{x}$ is as follows.

$$
\mathrm{Z}_{\mathrm{x}}=\mathrm{F}(\mathrm{x}+\mathrm{P})-\mathrm{F}(\mathrm{x})=\int_{x}^{x+\mathrm{P}} f(x) \mathrm{d} x
$$

Where: P means pitch.

Affected by the collar shoulder, the preload makes pin compressed. Decrement of Micro-P (in order to study the 


\section{International Journal of Science and Research (IJSR) \\ ISSN (Online): 2319-7064 \\ Index Copernicus Value (2013): 6.14 | Impact Factor (2014): 5.611}

thread, one thread can be regarded as a unit, then consider $\mathrm{P}$ small enough) is assumed to be $\Delta \mathrm{P}_{\mathrm{px}}$. While box is stretched, whose elongation is assumed to be $\Delta \mathrm{P}_{\mathrm{bx}}$.

$$
\begin{array}{r}
\Delta \mathrm{P}_{\mathrm{px}}=-\frac{\mathrm{P}}{E A_{p x}} \int_{0}^{x} f(x) \mathrm{d} x \\
\Delta \mathrm{P}_{\mathrm{bx}}=\frac{\mathrm{P}}{E A_{b x}} \int_{0}^{x} f(x) \mathrm{d} x
\end{array}
$$

Where: $E$ means Young's modulus, $A_{p x}$ and $A_{b x}$ represent $\mathrm{X}$-sectional area of the pin joint and box joint, respectively.

Since Micro-P is small enough, according to the definition of the derivative, Eq. (2) can be converted into as follows:

$$
Z_{x}=F(x+P)-F(x)=F^{\prime}(x) P=f(x) P
$$

Similarly, the load acting on the threads at $\mathrm{x}+\mathrm{P}$ can be obtained.

$$
Z_{x+P}=F(x+2 P)-F(x+P)=f(x+P) P
$$

Therefore, the load difference between $\mathrm{x}+\mathrm{P}$ and $\mathrm{x}$ is as follows:

$$
\Delta Z_{x}=Z_{x+P^{-}} Z_{x}=f(x+P) P-f(x) P=f^{\prime}(x) P
$$

Assumed the flexibility of threads at $x$ is $U_{x}$, deformation of the threads when stand a unit load, and load acting on threads makes pitch of pin at $\mathrm{x}$ increased by $\Delta \mathrm{P}_{\mathrm{tpx}}$ and pitch of box at $\mathrm{x}$ reduced by $\Delta \mathrm{P}_{\mathrm{tbx}}$. Then,

$$
\begin{gathered}
\Delta \mathrm{P}_{\mathrm{tpx}}=\mathrm{U}_{\mathrm{x}} \Delta \mathrm{Z}_{\mathrm{x}}=\mathrm{U}_{\mathrm{x}} \mathrm{f}^{\prime}(\mathrm{x}) \mathrm{P}^{2} \\
\Delta \mathrm{P}_{\mathrm{tbx}}=-\mathrm{U}_{\mathrm{x}} \Delta \mathrm{Z}_{\mathrm{x}}=-\mathrm{U}_{\mathrm{x}} \mathrm{f}^{\prime}(\mathrm{x}) \mathrm{P}^{2}
\end{gathered}
$$

Pin and box emerge axial deformation after preloaded. However, both of them are meshed with each other, which makes pitch of box and pin always equal. That is to say, it is necessary for box and pin to meet the above conditions, deformation compatibility, so that they can mesh together. According to this theory, the deformation compatibility equation of box and pin under preload after clicked can be obtained.

$$
\Delta \mathrm{P}_{\mathrm{px}}+\Delta \mathrm{P}_{\mathrm{tpx}}=\Delta \mathrm{P}_{\mathrm{bx}}+\Delta \mathrm{P}_{\mathrm{tbx}}
$$

Make the Eq. (3), (4), (8) and (9) substitute in Eq. (10). The above formula rearranges:

$$
2 \mathrm{PU}_{\mathrm{x}} \mathrm{f}^{\prime}(\mathrm{x})-\frac{1}{E} \frac{1}{A_{p x}}+\frac{1}{A_{b x}} \int_{0}^{x} f(x) \mathrm{d} x=0
$$

Make assumptions:

$$
\left.\mathrm{V}_{\mathrm{x}}=\frac{1}{E} \frac{1}{A_{p x}}+\frac{1}{A_{b x}}\right), \mathrm{W}_{\mathrm{x}}=\frac{U_{x}}{V_{x}}
$$

Where: $\mathrm{V}_{\mathrm{x}}$ is the sum of flexibility of box and pin;

$\mathrm{W}_{\mathrm{x}}$ is the ratio of threads deformation flexibility to casing joint stretching flexibility. Take derivation of the right and left of Eq. (11), this formula rearranges:

$$
2 P W_{x} f^{\prime \prime}(x)+2 P W_{x}^{\prime} f^{\prime}(x)-f(x)=0
$$

Consider $\mathrm{W}_{\mathrm{x}}$ and $\mathrm{W}_{\mathrm{x}}{ }^{\prime}$ with a little changes along $\mathrm{x}$, therefore the Eq. (12) can be regarded as a second-order homogeneous linear differential equation with constant coefficients, whose solution forms is as follows:

$$
\mathrm{f}(\mathrm{x})=\mathrm{C}_{1} e^{r_{1} x}+\mathrm{C}_{2} e^{r_{2} x}
$$

Then:

$$
\begin{aligned}
\mathrm{r}_{1}= & \frac{-\mathrm{P} W_{x}^{\prime}+\sqrt{\mathrm{P}^{2} W_{x}^{\prime 2}+2 \mathrm{P} W_{x}}}{2 \mathrm{P} W_{x}} \\
\mathrm{r}_{2}= & \frac{-\mathrm{P} W_{x}^{\prime}-\sqrt{\mathrm{P}^{2} W_{x}^{\prime 2}+2 \mathrm{P} W_{x}}}{2 \mathrm{P} W_{x}}
\end{aligned}
$$

Where: $r_{1}$ and $r_{2}$ are amounts about $W_{x}$.

When $\mathrm{x}=0, \int_{0}^{x} f(x) \mathrm{d} x=0$. Substitute it into Eq. (11), can obtain a boundary conditions:

$$
\left.f(x)^{\prime}\right|_{x=0=0}
$$

There is another boundary condition:

$$
\int_{0}^{\mathrm{L}} f(x) \mathrm{d} x=\mathrm{F}_{\mathrm{m}}
$$

Where: $\mathrm{L}$ is the length of threads engagement between box and pin;

$F_{m}$ is resultant of preload and support reaction of collar shoulder, that is, equivalent preload. Substitute Eq. (14) and (15) into Eq. (13), obtain the solution of it:

$$
\begin{aligned}
\mathrm{C}_{1}= & \frac{r_{1} r_{2}^{2} F_{m}}{r_{2}^{2}\left(e^{r_{1} \mathrm{~L}}-1\right)-r_{1}^{2}\left(e^{r_{2} \mathrm{~L}}-1\right)} \\
\mathrm{C}_{2}=- & \frac{r_{1}^{2} r_{2} F_{m}}{r_{2}^{2}\left(e^{r_{1} \mathrm{~L}}-1\right)-r_{1}^{2}\left(e^{r_{2} \mathrm{~L}}-1\right)}
\end{aligned}
$$

Therefore, the load distribution function along the $\mathrm{x}$ direction can be obtained, which is about box and pin affected by make-up torque. 


\section{International Journal of Science and Research (IJSR) \\ ISSN (Online): 2319-7064}

Index Copernicus Value (2013): 6.14 | Impact Factor (2014): 5.611

$$
\mathrm{f}(\mathrm{x})=\frac{r_{1} r_{2} F_{m}\left(r_{2} e^{r_{1} x}-r_{1} e^{r_{2} x}\right)}{r_{2}^{2}\left(e^{r_{1} \mathrm{~L}}-1\right)-r_{1}^{2}\left(e^{r_{2} \mathrm{~L}}-1\right)}
$$

If consider $\mathrm{W}_{\mathrm{x}}$ with a little changes, draw a conclusion: $\mathrm{W}_{\mathrm{x}}{ }^{\prime}$ $\approx 0$. Then $r_{1}=-r_{2}=r$, and Eq. (16) can be simplified:

$$
\mathrm{f}(\mathrm{x})=\frac{r F_{m}\left(e^{r x}+e^{-r x}\right)}{e^{r \mathrm{~L}}-e^{-r \mathrm{~L}}}=\frac{r F_{m} \operatorname{ch}(r x)}{s h(r \mathrm{~L})}
$$

Where: $\mathrm{r}=\sqrt{\frac{V_{x}}{2 \mathrm{P} U_{x}}}$;

$\mathrm{f}(\mathrm{x})$ is a hyperbolic cosine function.

\section{Finite Element Analysis}

\subsection{Make IUp}

Select casing joint as research object. Establish a reference point in an axial of end surface of casing, and couple this surface with the reference point. Moment and torque acted on casing will be loaded on the reference point. Fix the screwless terminal of collar. Interactions adopt common contact.

From the point of view of stress distribution, TP-CQ casing stress values along the threads direction of rotation decreases, and the max is in the last engagement thread of the small end of the casing. Select any one of the sections through the axis

(as Figure2) , this conclusion coincides with results of the Eq. (17), which illustrate the correctness of the establishing model.

Common API casing has no axial "resist the action" of collar shoulder, whose threads generate more circumferential interference than special casing under make-up, so that it has a greater amount of deformation. According to the Figure 3, conclusions can be drawn. Before the material yield has occurred, under the same torque, common API casing has a larger max stress than TP-CQ casing; API casing under $12 \mathrm{KN}$.m torque, its max stress is $761 \mathrm{MPa}$, while TP-CQ casing under $17 \mathrm{KN}$.m torque, his max stress is $760 \mathrm{MPa}$ (material yield strength is $758 \mathrm{MPa}$ ), all of which show that TP-CQ casing has greater torsion strength than API casing.

Applied different torques, the best make-up torque of casing can be obtained when Mises stress reaches $80 \%$ of the material yield strength. Interpolating value to the curve of Figure3, the best make-up torque of API is $9.23 \mathrm{kN}$.m while of TP-CQ is $14.31 \mathrm{KN}$.m. Due to collar shoulder, the torsion strength of casing improves by 55\%.Regarding the max stress of each turn of the threads as its stress, number the casing threads from small to big end. Appling $10 \mathrm{kN}$.m torque to both casings, the stress distribution curve of each thread turn can be obtained, depicted in Figure4.

Figure4 shows that due to exists of collar shoulder, stress distribution of each thread turn of TP-CQ casing significantly different from API casing under the same torque. Stress of API casing thread under torque is mainly in the first four threads turns. With the number increasing, its value reduces, which can be expressed as a "ramp curve"; while stress of TP-CQ casing threads under torque can be considered as a "Basin-shaped curve", whose last three threads turns also have some stress. Obviously, stress of API thread is larger than TP-CQ thread in the corresponding number of turns.

When made up, TP-CQ casing precesses along the direction of threads, of which largest contact pressures appears on the threads before the end of casing reaches collar shoulder, API with similar situations. As the torque increases, the end of casing and collar shoulder, sealing surface of casing and collar shoulder gradually contact but not emerge interference fit; as torque continues to increase, the contact pressures between them quickly increase and they become the largest region of the contact pressures; sealing effect of TP-CQ casing mainly comes from the interference fit between sealing surface of casing and collar. The larger torque is, the larger interference is, and the greater the contact pressures are. Size of make-up torque determines the initial contact pressures of casing. If too small, threads sealing performance can't meet targets; if too large, it is prone to cause galling and threads failure. So when calculating, this two casings are both applied to the best make-up torque. After clicked, the contact pressures distribution of TP-CQ casing sealing surface from left to right is shown in Figure5. The max contact pressures of this figure will determine the sealing performance of TP-CQ casing.

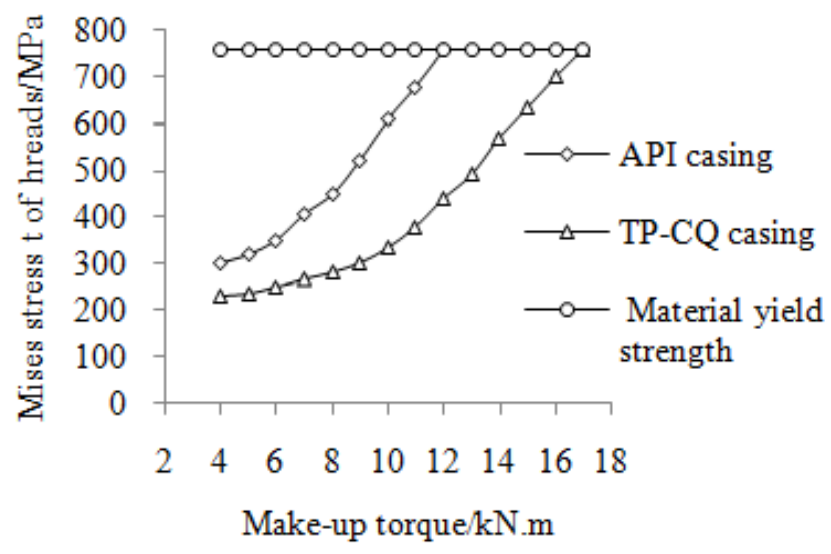

Figure 3: The max stress of casing threads after clicked

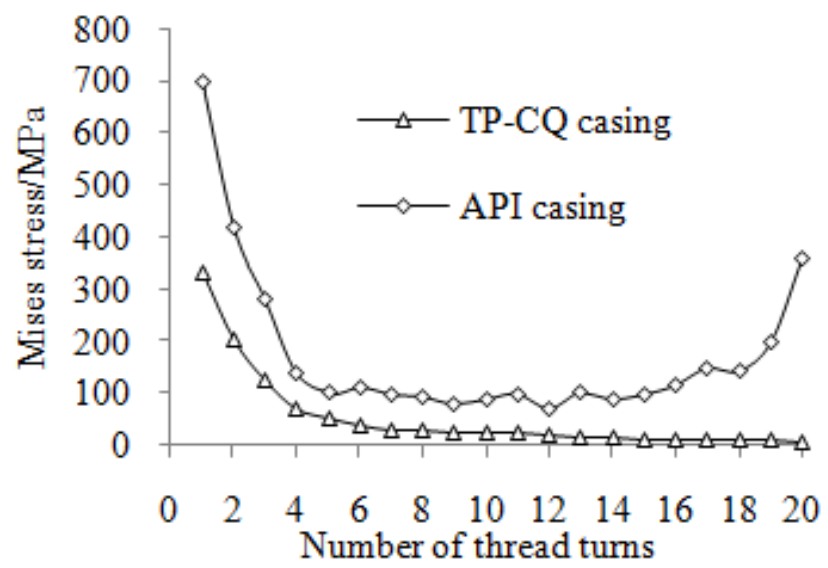

Figure 4: Stress distribution curve of each thread turn of both casings under $10 \mathrm{kN}$.m torque 


\section{International Journal of Science and Research (IJSR) \\ ISSN (Online): 2319-7064}

Index Copernicus Value (2013): 6.14 | Impact Factor (2014): 5.611

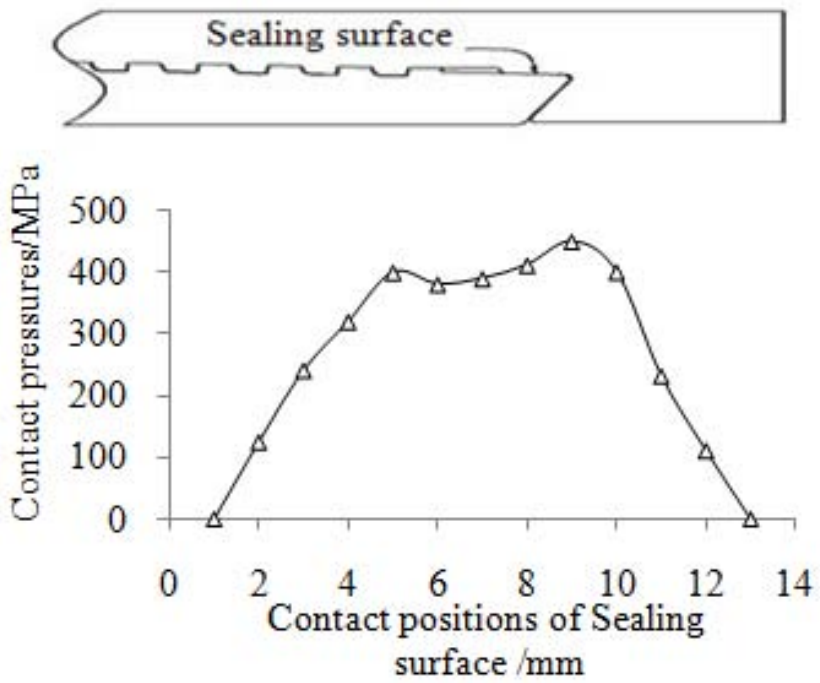

Figure 5: The contact pressure distribution of the sealing surface

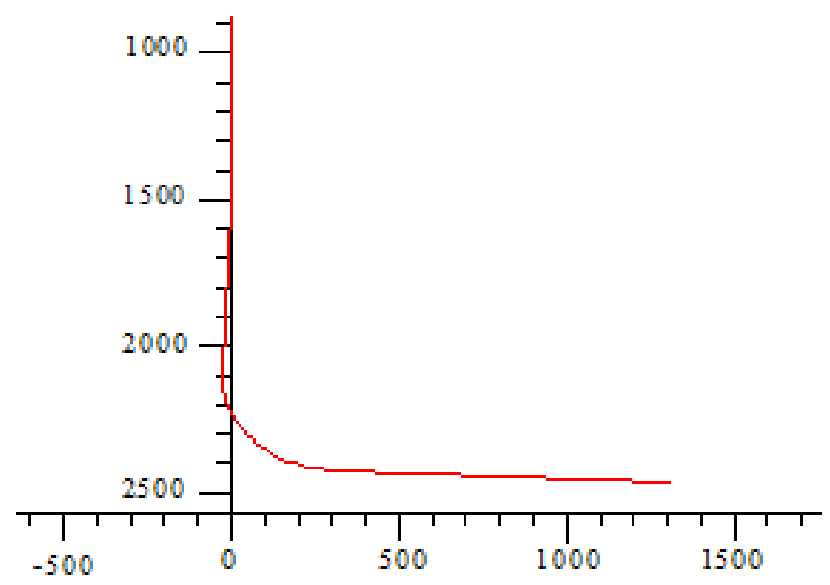

Figure 6: Example in this paper, vertical sectional view of shale gas wells

API casing relies on both sides of threads contact pressures and grease to seal together. However, under high temperature and pressure environments, threads grease is likely to be volatile, degenerative and eroded so that API casing is not applicable for deep and ultradeep well any more. The sealing performance of TP-CQ casing depends on contact pressures of sealing surface. But around the wellhead, with very large axial tension, the magnitude of interference between end surface of casing and collar shoulder, casing sealing surface and collar sealing surface will be small. Even emerge situation as mating surface separation. Then collar sealing effect is reduced or lost. Therefore, using TP-CQ casing at the wellhead is a waste, and it would not work as it is. Thus this paper suggests using the two casings together. That is to say, use API casing for shallow or around of the wellhead, while use TP-CQ casing for large deep well. How to distinguish the deep as small or large? The following will calculate the actual working conditions to obtain depth range of "small or large".

\subsection{Different Cases of Casing Corresponding to Well Depth}

After clicked and set into well, casing is mainly affected by axial tension, internal and external pressures, as well as moment, at bent well section.
Table 1: Working conditions corresponding to vertical segments

\begin{tabular}{|c|c|c|c|}
\hline Depth & $\begin{array}{c}\text { Axial } \\
\text { tension/N }\end{array}$ & $\begin{array}{c}\text { Internal } \\
\text { pressure } \\
\text { /MPa }\end{array}$ & $\begin{array}{l}\text { External } \\
\text { pressure } \\
\text { /MPa }\end{array}$ \\
\hline 0 & $1.68 \times 106$ & 26.16 & 0 \\
\hline $500 \mathrm{~m}$ & $1.33 \times 106$ & 26.99 & 10.29 \\
\hline $1000 \mathrm{~m}$ & $9.82 \times 105$ & 27.83 & 20.59 \\
\hline $1500 \mathrm{~m}$ & $6.33 \times 105$ & 28.70 & 30.88 \\
\hline
\end{tabular}

Note: Working conditions in the table according to different depth of well are assumed as case 1 , case $2 \ldots$ case 4 .

Table 2: Working conditions corresponding to curved segments

\begin{tabular}{|c|c|c|c|c|}
\hline $\begin{array}{c}\text { Depth } \\
\text { Vertical } \\
\text { depth }\end{array}$ & $\begin{array}{c}\text { Axial } \\
\text { tension/N }\end{array}$ & $\begin{array}{c}\text { Internal } \\
\text { pressure } \\
/ \mathrm{MPa}\end{array}$ & $\begin{array}{c}\text { External } \\
\text { pressure/MPa }\end{array}$ & Curvature \\
\hline $\begin{array}{c}1737 \mathrm{~m} \\
1700 \mathrm{~m}\end{array}$ & $4.91 \times 10^{5}$ & 29.05 & 35.01 & $\begin{array}{c}0.97^{\circ} \\
/ 30 \mathrm{~m}\end{array}$ \\
\hline $\begin{array}{c}1980 \mathrm{~m} \\
1900 \mathrm{~m}\end{array}$ & $3.54 \times 10^{5}$ & 29.40 & 39.12 & $\begin{array}{c}4.39^{\circ} \\
/ 30 \mathrm{~m}\end{array}$ \\
\hline $\begin{array}{c}2654 \mathrm{~m} \\
2390 \mathrm{~m}\end{array}$ & $1.25 \times 10^{4}$ & 30.30 & 49.21 & $\begin{array}{c}7.09 \\
/ 30 \mathrm{~m}\end{array}$ \\
\hline $2769 \mathrm{~m}$ \\
$2408 \mathrm{~m}$
\end{tabular}

Note: Working conditions in the table according to different depth of well are assumed as case 5 , case 6 ...case 8

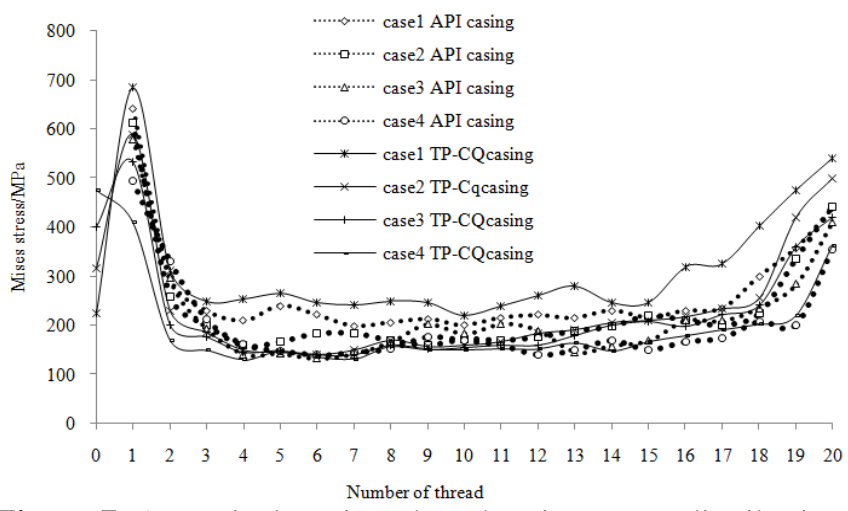

Figure 7: At vertical section, threads Mises stress distribution

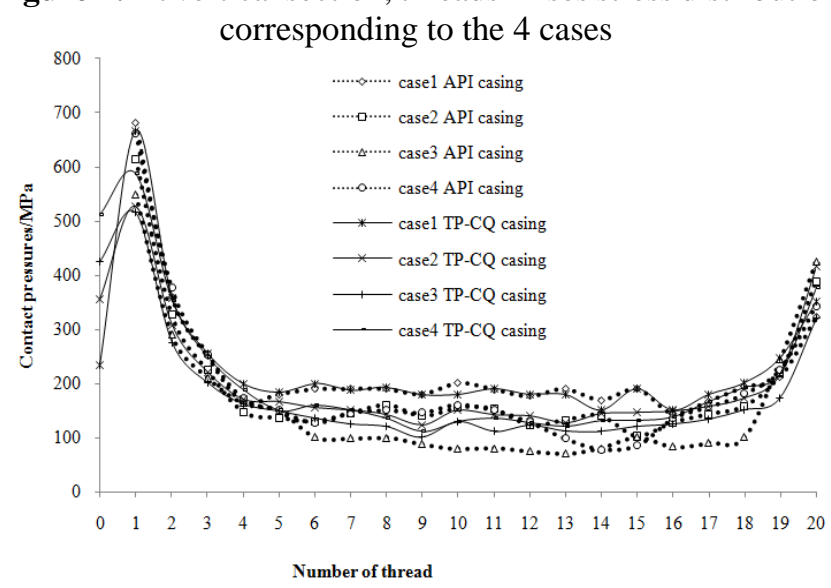

Figure 8: At vertical section, threads contact pressures distribution corresponding to the 4 cases

Generally, in addition to its self-weight, casing axial tension 


\section{International Journal of Science and Research (IJSR) \\ ISSN (Online): 2319-7064 \\ Index Copernicus Value (2013): 6.14 | Impact Factor (2014): 5.611}

consists of friction drag between tube skin of bending section and cement mantle, and residual stress after cemented. But, generally, only consider the self-weight in the calculation, while take the above other loads into consideration in the form of safety factors.

When applied to axial tension, casing is attenuated and elongated, of which pitch diameter will be decreased. As for collar corresponding mating to casing, its cross-sectional areas of threads are larger than casing. Then the threads deformation of casing is smaller than collar. So affected by axial tension, the gaps between thread root and crest will increase. In order to ensure sealing performance, only fill adequate grease into the gaps.

External pressure is composed of drilling fluid pressures, cement slurry column pressures, fluid pressure of formation and side pressures of flowing formation etc. At the joints, only collar is directly affected by external pressure, which makes collar radial contraction but casing not. So threads of collar and casing tightly fit together. Internal pressure of casing string consists of some pressures, including drilling fluid, formation fluid, applied to when special operations, with similar function to external pressure.

At the inclined segment, casing certainly produces bending deformation and threads will be affected by moment. Under moment, symmetry of stress change. The threads load distribution of tensile edges distinct from compressive edges, which affects thread sealing performance, not weaker than internal and external pressures. Adopt curvature to simulate the moment, whose value comes from logging data of wellbore trajectory.

In this paper, set the horizontal well, shown in Figure6, as an example to discuss connection strength and sealing performance of the two casings. Select both 4 working conditions, depicted as Table 1and Table 2, of vertical and curved segments to analyze.

Conclusions can be drawn from the working condition table. Axial tension decreases with well depth increasing: When depth is 0 , at the wellhead, it has max value; internal pressure mainly generates from shale gas in the vertical direction, with little change, which increases with depth increasing; external pressure has the same change trend as internal pressure, however, more degree than internal pressure. At the wellhead, the external pressure is 0 . While at bottom, its value reaches maximum.

\subsection{Results and Analysis}

In order to be convenient for recording and comparing, make an assumption that sealing surface of TP-CQ casing is considered to be No.0 thread. At vertical section, under different working conditions of well depth, casing thread stress distribution shown in Figure7, and contact pressures is shown in Figure 8.

Observe separately the stress distribution of the two casings, some agreements can be reached. As for threads stress distribution of API casing, it's expressed as "basin-shaped" curve. With the well depth increasing, stress on the same threads almost decreases and the max emerges in the "No. 1" thread; As for TP-CQ casing, it is similar to API, but contrary to its sealing surface. Compare with the two distributions. Under case 1, threads stress of TP-CQ casing is larger than API. Under case 2, threads stress of TP-CQ casing is less than API, the same as case 3 and case 4 . Under case 1 , threads max stress of TP-CQ casing is $684 \mathrm{MPa}$, while API casing is $641 \mathrm{MPa}$. It shows that in the vicinity of the wellhead, tensile strength of TP-CQ casing is weaker than API casing, contrary to other segments. It is because of the existence of collar shoulder that the casing threads bear more axial compression. With well depth increasing, the "shoulder effect for stress" is weakened. However, due to reduction of axial tension, the initial amount of interference resulting from make-up increases, and makes the stress of the sealing surface increase.

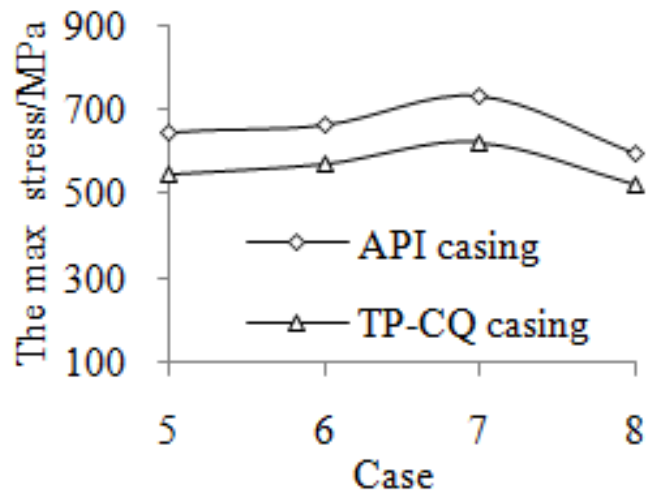

Figure 9: Under different case, the max stress of two casings

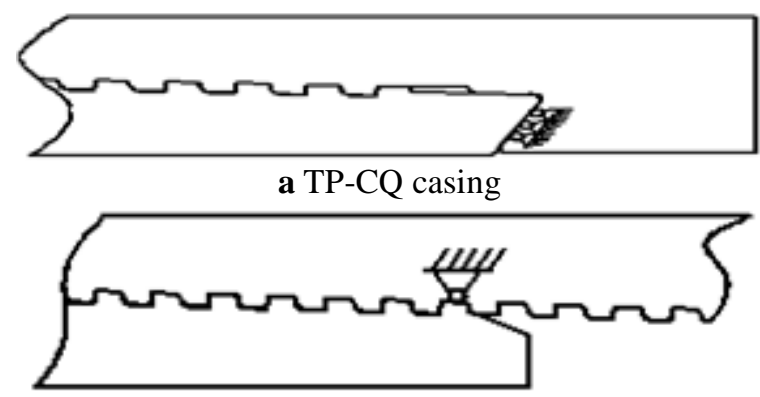

b API casing

Figure 10: Case of casing fulcrum

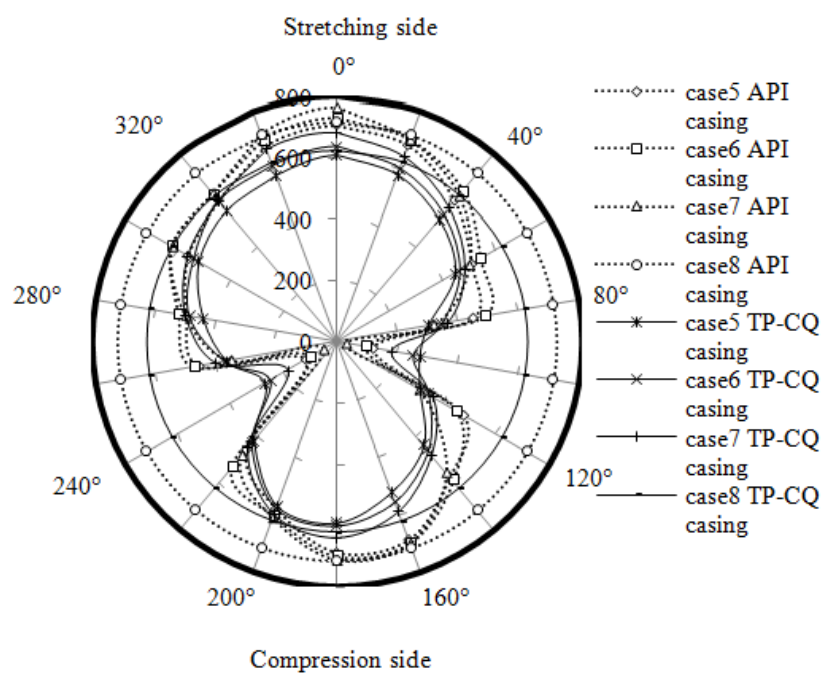

Figure 11: The contact pressures distribution about "No. 1" thread of API casing and "No. 0"thread of TP-CQ casing

Table 3: Comparison of $K$ and min contact pressures between 


\section{International Journal of Science and Research (IJSR) ISSN (Online): 2319-7064 \\ Index Copernicus Value (2013): 6.14 | Impact Factor (2014): 5.611}

\begin{tabular}{|c|c|c|c|c|c|}
\hline \multicolumn{2}{|c|}{$\begin{array}{ll}\text { Case } \\
\text { Kinds of casing }\end{array}$} & $\begin{array}{c}\text { Case } \\
5\end{array}$ & $\begin{array}{c}\text { Case } \\
6\end{array}$ & $\begin{array}{c}\text { Case } \\
7\end{array}$ & $\begin{array}{c}\text { Case } \\
8\end{array}$ \\
\hline \multirow{3}{*}{$\begin{array}{c}\text { API } \\
\text { casing }\end{array}$} & $\begin{array}{c}\text { Min contact } \\
\text { pressures /MPa }\end{array}$ & 121 & 98 & 31 & 715 \\
\hline & $\begin{array}{c}\text { Internal pressures } \\
/ \mathrm{MPa}\end{array}$ & 29.1 & 29.4 & 30.3 & 30.3 \\
\hline & $K$ & 4.82 & 6.42 & 13.9 & 0 \\
\hline \multirow{3}{*}{$\begin{array}{l}\text { TP-CQ } \\
\text { casing }\end{array}$} & $\begin{array}{c}\text { Min contact } \\
\text { pressures } / \mathrm{MPa}\end{array}$ & 273 & 251 & 180 & 621 \\
\hline & $\begin{array}{c}\text { Internal pressures } \\
/ \mathrm{MPa}\end{array}$ & 29.0 & 29.4 & 30.3 & 30.3 \\
\hline & $K$ & 1.23 & 1.53 & 2.77 & 0 \\
\hline
\end{tabular}

tension, so that stress distribution of threads is not uneven, seriously affecting the connection strength and sealing performance of the casing. Under case5, 6 and 7, curvature of casing gradually increases in order. Case 7 has the max curvature, and case 8 is the working condition close to the horizontal section. Here not discuss the distribution of stress on the threads. Whether connection failure happens or not is determined by comparing the max stress with yield strength. At inclined segment, under these 4 cases, the max stress is shown in Figure9.

Two curves have the same trend, "arch-type". As for inclined segment working conditions, axial tension becomes more and more small, but curvature grows. Under case 7, with the max curvature, the max stress of two casing reaches maximum. Moments turn out to be of great influence on stress for casing. Clearly, under the same working conditions, the stress of TP-CQ casing is smaller than API casing. The existence of collar shoulder makes the end of TP-CQ casing constrained. As long as the end of casing surface, "No.0" thread, does not leave the collar shoulder, it can be considered as the fulcrum by the principle of leverage; API casing collar with no shoulder, it is clearly that his fulcrum is the "No.1" thread, shown in Figure10. Under the same curvature, of course, the greater moment arm is, the smaller the force is. Finite element's results show that at inclined segment, both max stress and max contact pressures of TP-CQ casing appear in the "No.0" thread, while of API casing appear in "No.1" thread.

At inclined segment, under bending moment, one side of casing suffers from pressures, and the other side suffers from

Table 4: Selection of casing at different well depth

\begin{tabular}{|c|c|c|c|c|c|}
\hline Well depth & \multirow{2}{*}{ 0 500m } & $500 \mathrm{~m} \sim 150 \mathrm{~m}$ & $1500 \mathrm{~m} \sim 1737 \mathrm{~m}$ & $1737 \mathrm{~m} \sim 2654 \mathrm{~m}$ & $2654 \mathrm{~m} \sim 2769 \mathrm{~m}$ \\
\hline API & $\sqrt{ }$ & $\sqrt{ }$ & $\sqrt{ }$ & \\
\hline TP-CQ & & & & $\sqrt{ }$ & $\sqrt{ }$ \\
\hline
\end{tabular}

Select "No. 1" thread of API casing and "No. 0" thread of TP-CQ casing to analyze. And apply polar coordinates to express the contact pressures corresponding location, the circumferential degree represented threads in circumference and the radial value represented contact pressures, MPa, shown in Figure11. When subjected to bending moment, volume of casing's compression side decreases, but stretching side increases. Therefore, the contact pressures are not symmetrical with direction of the bending moment, but "gourd-type". The ratio of stretching and compression area is related to moment, borehole curvature.

Under moment, it is obvious not that the greater contact pressures are, the better sealing effect is. Uniform contact pressures can uniformly disperse the leakage region, and greatly reduce the possibility of leakage. The uneven distribution of contact pressures will make the area with minimal contact pressures concentrated leak area. Under case $5,6,7$ in turn, the max contact pressures of the selected "thread" increases, while the min contact pressures reduces, which shows that the moment is larger , the gap between max and min contact pressures become larger.
There is a formula to represent the relative span K, Gap, between the max and min contact pressures:

$$
\mathrm{K}=\frac{\frac{y-x}{x}}{x}=-1+\frac{\frac{y}{x}}{(\mathrm{y} \geq \mathrm{x}>0)}
$$

Where: $\mathrm{y}$ is the max contact pressures; $\mathrm{x}$ is the min contact pressures; Value of $\mathrm{K}$ is a quantitative characterization of rang that moment makes casing sealing performance decrease. The larger its value is, the more obvious the effect of moment is.

When $\mathrm{y}$ is constant, $\mathrm{K}$ is a hyperbolic about $\mathrm{x}$. The smaller $\mathrm{x}$ is, the larger $\mathrm{K}$ is, $\mathrm{K} \in[0,+\infty)$. When $\mathrm{x}$ is constant, $\mathrm{K}$ is a straight line about $\mathrm{y}$. The larger $\mathrm{y}$ is, the larger $\mathrm{K}$ is, $\mathrm{K} \in[0$, $+\infty)$.That is to say, when the max contact pressures are constant, the smaller the min contact pressures are, the more obviously casing sealing effect declines. When the min contact pressures are constant, the larger the max contact pressures are, the more obviously casing sealing effect declines. Practical, on engineering, due to property restrictions of materials, $\mathrm{K}$ will not grow indefinitely. $\mathrm{K}$ reaches to a certain value, the sealing effect of casing rapidly 


\section{International Journal of Science and Research (IJSR) \\ ISSN (Online): 2319-7064 \\ Index Copernicus Value (2013): 6.14 | Impact Factor (2014): 5.611}

decrease or even completely lose. $\mathrm{K}$ is too small to meet the horizontal displacement of the gas wells; and too large to meet connection and sealing effect, even fail. So must control the value of $\mathrm{K}$, and the fundamental problem lies in the moment casing applied. When the min contact pressures can meet the sealing requirement, of course, selecting a kind of casing with smaller $\mathrm{K}$ benefits more. Analyzing Table 3, under all cases, the min contact pressures are larger than the internal pressure. Only under case 7 , the min contact pressures of API casing close to the internal pressure, this case likely leak.

According to value of $\mathrm{K}$, can know moment has the largest effect on the sealing in case 7 . Under case 7 , the ratio of contact pressures and internal pressure, sealing safety factor, is minimal relative to other case. Case 7 turns out to be the most dangerous case. Comparing with two casings, under same the case, API casing has a larger K than TP-CQ casing. Taking all the factors into consideration, a conclusion can be drawn, there is a great moment applied, TP-CQ casing obviously has advantages over API casing.

At bottom horizontal segment, casing mainly applied to internal and external pressure, the contact pressures of API casing is slightly larger than TP-CQ casing. However, at bottom horizontal segment, Casing will face high temperature, high pressure, and highly corrosive environments. Under complex conditions, the ability to work of TP-CQ casing is far stronger than API casing.

\section{Conclusion}

In this paper, study how the make-up affects connection and sealing of two casings; comparatively analyze the connection strength and sealing performance between two casings, under different well depth respectively.

After clicked, the threads stress distribution of API casing differences from TP-CQ casing. Stress of TP-CQ casing is mainly on former 4 threads, while API casing is mainly on former and latter 3 threads. Size of make-up torque has a great impact on the connection and sealing. On the project, shall be applied the best make-up torque for clicking.

Around the wellhead, at $0 \sim 500 \mathrm{~m}$ well depth, connection strength of TP-CQ casing is weaker than API casing, but the sealing performance insignificant; at $500 \mathrm{~m} \sim 1500 \mathrm{~m}$ well depth, connection strength of TP-CQ casing is slightly larger than API casing, the same as sealing performance, with no obvious advantage; at $1500 \mathrm{~m} \sim 1737 \mathrm{~m}$ well depth, casing beginning to suffer from bending moment, the curvature is also very small, and internal and external pressure significantly enhance. TP-CQ casing, at this time, has little large advantages on connection and sealing, but API casing also applied to this well segment; at $1737 \mathrm{~m} \sim 2654 \mathrm{~m}$ well depth, because of the bending moment, sealing performance of API casing cannot meet the requirements of sealing for shale gas; at 2654m 2796m well depth, Casing is almost on horizontality, without bending moments and axial load. However, the bottom complex working environment will soon make API casing eroded, TP-CQ casing as the better choice; when both of two casings are applicable, will consider the cost. The final selections are summarized in Table 4 .

These conclusions for casing selection of other shale gas well can also play a guiding role. That is to say, at small well depth, 0 500m, use API casing; at light bending segment, it is necessary to compare with ratio of performance and price between two casings; in this paper, at $1500 \mathrm{~m} \sim 1737 \mathrm{~m}$ well depth, performance advantages of TP-CQ casing is clearly insufficient to cover its cost; when at the large moment segment, should use TP-CQ casing; in the bottom of the well, also select TP-CQ casing.

\section{References}

[1] America Petroleum Institute: BUL 5C3. Bulletin on Formulas and Calculations for Casing, Tubing, Drill Pipe, and Line Pipe properties. API, USA, 1994:16-18.

[2] Chen P. Drilling and Completion Engineering [M].Beijing: Petroleum Industry Press, 2005(in Chinese).

[3] Dvorkin E N, Toscano R G. Finite Element Models in the Steel Industry, Part II: Analyses of Tubular Products Performance $[\mathrm{J}]$.Computers \& Structures, 2003, 81(8 - 11): 575 - 594.

[4] Eiji Tsuru, Kazushi Maruyama. Allowable Torque of Tubular Connection under Simulated Running and Working Conditions[S].1995 SPE/ I A DC Drilling Conference. American, 28 February -2 March 1995:205 -214 .

[5] Gabriel Carcagno. The design of tubing and casing premium connection for HTHP wells [M].2005 S PE workshop in high pressure / high temperature sour design. T X, U. S. A., 2005: 17 -19.

[6] Gao LX, Jin Y. Seal design of premium threaded casing connection [J].Chinese Journal of Mechanical Engineering, 2005, 41 （3）:216- 219(in Chinese).

[7] Guo JH, Ma FM. Air tightness performance assessment of screw threads of oil tubings in high-sulfur gas wells in the Longgang Gas Field, Sichuan Basin [J].Natural Gas Industry, 2013, 33(1):128-131(in Chinese).

[8] Kwon W Y, Klementich E F, Ko I K.An efficient and accurate modal for the structural analysis of threaded tubular connections[J]. SPE Production Engineering, 1990, 5(4):261-264

[9] Liu JB, Zhang W, Wang SY. Mechanics analysis and design of connecting thread in casing drilling [J].Daqing Petroleum Institute, 2006, 30(1):47- 49(in Chinese).

[10] Liu XQ, Chen GM, Chang YJ, Zhang L, Zhang WG, Xie $\mathrm{H}, 2014$.Multistring analysis of wellhead movement and uncemented casing strength in offshore oil and gas wells. 
Petroleum Science, (1):131 138(in Chinese).

[11] Santus C, Bertini L, Beghini M, Merlo A, Baryshnikov A. Torsional strength comparison between two assembling techniques for aluminium drill pipe to steel tool joint connection [J].International Journal of Pressure Vessels and Piping, 2009, 86: 177-186.

[12] Schwind B. Mobile qualifies three tubing/casing connection product lines [J].Hart's Petroleum Engineer International, 1998, 71 (11):59-62.

[13] Shi MY, Gao XS, Li YL, Li FP. The FEM Analysis of Thread Buckled State for Expandable Casing [J].Pipeline Technique and Equipment, 2012(5): 4-5+9(in Chinese).

[14] Wang L, Zhang RX, Liu YW, Zou JX, Zang Y, Zou WZ, $\mathrm{Lu} \mathrm{XQ}$. Gluing failure analysis of API round thread casing connection [J].Iron and Steel, 2000, 5 (35):44-47(in Chinese).

[15] Wang LS, Liao SM, Chen GS, Guo GA, Lü ZG, Fu YQ. Bottlenecks and countermeasures in shale gas exploration and development of China [J].Natural Gas Industry, 2011, 31(12):119-122(in Chinese).

[16]Wang L, Zang Y, Chen ZN, et al. Modal analysis of thread off failure of oil round thread casing connection[J].Journal of University of Science and Technology Beijing. 2001, 8(4):277-279(in Chinese).

[17] Wang XH, Feng YR, Li HL. Method for calculating load on threads of drill tool connection [J].China Petroleum Machinery, 1998, 26 (8) : 49- 52(in Chinese).

[18] Wittenberghe J V, Baets P D, Waele W D, et al. Numerical and Experimental Study of the Fatigue of Threaded Pipe Couplings[C]//BREBBIA C A. Surface Effects and Contact Mechanics IX: Computational Methods and Experiments. Southampton, UK: WIT Press, 2009: 125 - 129Yang GG, Tao Q, Liu W, Ding SD, Ma P. Research on the Running and Centralization of Casing in Shale Gas Well [J].China Petroleum Machinery, 2012, 40(10):26-30(in Chinese).

[19] Yu H, Zhang LH, Lin TJ. Finite Element Analysis of Failure Mechanism of Casing during Shale Gas Fracturing [J].China Petroleum Machinery, 2014, 42(8):84-88(in Chinese).

[20]Zhu HJ, Lin YH, Zeng DZ, Zhang DP, Wang F,2012. Calculation analysis of sustained casing pressure in gas wells. Petroleum Science, (1):66 74(in Chinese 